\title{
Dijitalleşme ve Bilişim Teknolojilerinin Çalışanlar Üzerindeki Etkileri
}

Betül ERSÖZ, Gazi Üniversitesi Rektörlük, Doktora Öğrencisi, betul.ersoz@gazi.edu.tr, (DD 0000-00016221-1530

Mehmet ÖZMEN, Mehmet Akif Ersoy Üniversitesi, Bucak Isşletme Fakültesi, Dr. Öğretim Üyesi, mehmetozmen@mehmetakif.edu.tr, (iD) 0000-0001-6369-8686

20 yıl öncesine kadar teknolojinin insanlara sunduğu firsatlar oldukça sinırlıydl. Günden güne evrensel ilerleme aracı olarak kullanılan bilişim teknolojileri bu firsatları artırarak, küreselleşen dünyanın vazgeçemediği bir unsur haline gelmiştir. Günümüzde dijitalleşmenin artması ile birlikte teknolojinin hızına yetişmek oldukça zordur. Dijital çă̆ olarak adlandıran teknoloji yüzyılı, bireylerin hayatların kolaylaştırırken yenilikler sunarak teknolojiye bağımlı bireyler haline dönüştürmüştür. Bilişim teknolojinin gelişmesi ile örgütler teknolojinin sunduğu araçlarl kullanarak çağın sunduğu olanaklart firsata dönüştürerek hem ulusal hem de uluslararası bir ilerlemenin parçası olmuştur. Örgütler 21.yüzyıl ile hızlı bir dönüşüme girerek teknolojinin sunduğu araçlart bünyelerine entegre etmişlerdir. Dolaylslyla, Dijitalleşme ve Bilişim teknolojilerinin çalışanlar üzerinde olumlu ve olumsuz etkilerinin olduğu görülmektedir. Çalışmanın amacı, dijitalleşme sürecinde meydana gelen dönüşümün çalışanların üzerinde bıraktığ etkiyi yapılan çalışmalar ışı̆̆ında inceleyerek, alanyazına katkı sağlamaktır.

Anahtar : $\quad$ Dijitalleşme, Bilişim Teknolojileri, Çalışanlar

Kelimeler

\section{The Effects of Digitalization and Information Technologies of Employees}

\begin{abstract}
Until 20 years ago, the opportunities offered by technology to people were very limited. Information technologies, which are used as universal progress tool day by day, have become an indispensable element of the globalizing world by increasing these opportunities. Today, with the increase in digitalization, it is quite difficult to keep up with the speed of technology. The technology century, which is called the digital age, has transformed individuals into technology-dependent individuals by offering innovations while facilitating their lives. With the development of information technology, organizations have become part of a national and international progress by turning the opportunities offered by the technology into opportunities by using the tools offered by technology. Organizations have entered a rapid transformation with the 21 st century and have been integrated into their bodies with the tools of technology. Accordingly, It is seen that digitalization and information technologies have positive and negative effects on employees. The aim of the study is to contribute to the literature by examining the effect of the transformation that occurred in the digitalization process on the employees in the light of the studies conducted.
\end{abstract}

Keywords:

Digitization, Information Technologies, Employees 


\section{GíRiș}

Sanayi devrimi ile insanoğlu köklü bir değişimin içerisine girmiş ve bu dönüşüm içerisinde hızla ilerlemeye devam etmektedir. Bundan 300 y1l öncesinde I. Sanayi dönemi, İngiltere'de bulunan tekstil sektöründeki küçük ölçekli işletme dokuma tezgahlarının mekanik bir şekile getirilmesi ile ekonomik gelişmeler, toplumsal, siyasi ve kültürel alanlarda da bir dizi köklü bütüncül dönüşüme neden olmuştur. Bu durum insanlık tarihinde yer alan önemli bir dönüşüm ile günlük hayatı tamamıyla birçok yönü ile etkisi altına almıştır (Oxford:290). Küçük ölçekli işletmeler gelişerek yerlerini fabrikalarabırakmışlardır.

20. yüzyıl ile birlikte II. Sanayi devrimi olarak nitelendirilen dönem başlamış, buhar enerjisine ek olarak elektrik ve petrol de üretim sürecine katılmıştır. 1970'lerden sonra yaşanan III. Sanayi Devrimi döneminde gittikçe önemi artan serileşme ve makineleşme kavramlarına ek olarak gelen otomasyon ve sayısallaşma kavramları eklenerek büyük dönüşüm süreci başlamıştır. Otomasyonun çoğalmasıyla üretim verimliliği yükselerek dijitalleşmeye başlayan dünyada bilginin ve ticaretin kapsamı ve sınırları ortadan kalkmıştır. İçinde bulunduğumuz dönem olan IV. Sanayi Devrimi, otomasyon üretimi ile bilgi ve iletişim teknolojilerinin bir aracı haline gelmiştir. IV. Sanayi Devrimi, çağdaş otomasyon sistemlerini, üretim teknolojilerini ve veri alışverişlerini kapsayan bir terimdir. Bu süreçte akıllı fabrika sisteminin oluşmasında büyük rol oynamaktadır. Sanayinin gelişim aşamasında buhar gücü ile çalışan sistemler kullanılırken, çağımızda bu sistemler, siber fiziksel sistemlere dönüşmüştür. Dijitalleşen dünya ile endüstri modelleri de bir değişime uğramıştır. Dijital çağ, mekân ve zaman kavramını ortadan kaldırmıştır. Sistem-İnsan etkileşimine dayalı çoğu alan bilişim ve matematik için temel bir unsur ve en önemli araştırma konusu olarak karşımıza çıkmıştır. Robotlar, Yapay zekâ teknolojisi, sensörler, Nesnelerin interneti (IoT), Endüstriyel sanayi, Bulut bilişim, Artırılmış gerçeklik gibi internet teknolojilerindeki devasa gelişmeler ve bütün bu teknolojilerin bulut bilişim ile birleşmesi neticesinde meydana gelen dijital ortamlar dünyay1 oldukça farklı bir dönüşümün eşiğine taşımaktadır. Bu teknolojiler günümüzün dijital dünyasında sıkça duyulan kavramlar ve uygulama alanları haline gelmiştir. Bununla birlikte, Almanya'da 2011 yılında yapılan teknoloji fuarında ortaya çıkan Endüstri

4.0 kavramının gündeme gelmesiyle bu teknoloji bütün dünyanın gündeminde yer almıştır. Çin'in üretim imkânlarının artması ile birlikte Avrupalı devletleri ekonomik anlamda sarsıntıya uğratmasından dolayı Almanların bu yönde hareket etmelerine sebep olmuştur. Teknolojinin zirvesinin olarak görülen Endüstri 4.0 'ın en geç yirmi yıl içinde tamamen uygulamaya geçeceği belirtilmektedir. Ancak, bu teknoloji ile ilgi bilgi birikimi oldukça azdır. Ülkeler bu teknolojiye yönelik araştırma birimleri kurmaya başlamıştır. 1980'lerde önemli bir çıkış yakalayan ve 2000'li yıllara kadar uzanan, sürekli gelişmekte olan enformasyon ve bilişim teknolojilerinin sunduğu dönüşüm ve gelişmelerin olduğu bu dönem post endüstriyel dönem olarak adlandırılmaktadır (Kurtulmuş, 2012: 161).

Dijitalleşmenin yaygınlaşmasıyla birlikte yenilik ve dönüşüm yaşanmasında bilişim teknolojileri (BT) adeta itici bir güç haline gelmiştir. BT'nin dijital dünyaya sunduğu teknolojik araçlar bu duruma zemin hazırlamıştır. BT’nin gücünü kullanmak, değişen dünyada daha da güçlü adımlar atmayı sağlamaktadır. Özellikle çalışma yaşamının da içinde olduğu dijital dünya da bilişim teknolojileri oldukça geniş bir yer edinmiştir. BT, çalışma yaşamını kolaylaştırarak gerek yazılım gerekse donanım araçları ile günlük işlemlerin ilerlemesi için en önemli unsur haline gelmiş̧ir. BT’nin ilerlemesi ile çeşitli meslek gruplarının iş yaşamındaki mesleki bilgi ve becerilerinin bu doğrultuda dönüşümün bir parçası olarak gelişmesi gerekmektedir. Bu beceriler ile bilgi birikimi üç başlık altında incelenmektedir. Öncelikle, bilgisayar ile ilgi donanım ve yazılımları kullanabilme becerisidir. İkincisi, problem çözme becerisi olup ve kavramsal-soyut akıl yürütme becerileri ile bilgisayarlar sembollerini bilmek bilginin etkin kullanılması bakımından ihtiyaç duyulmaktadır. Son olarak bilgisayarsız yapılan işlemlerde dahi, bilgisayar kullanımına bağlı iş alanındaki değişimlerden ötürü yeni iş tanım ve görevlerini kapsayan ortamlarda çalışabilme yetkinliğidir (Irwin ve Michael, 2003). Bu dönüşüm içerisinde çalş̧anlar, BT’ni $n$ 
getirdiği yenilere ayak uydururken, hem zihinsel hem psikolojik bazı yansımaların etkisinde kalmaktadır. Yaşamın sürekliğini sağlayan bir sosyal faaliyet olan çalışma yaşamı, bireylerin yaşamlarının merkezinde yer almaktadır. Teknolojinin gelişmesi ile ortaya çıkan küreselleşme kavramı çalışma yaşamını başka bir boyuta taşımıştır. Yapay zekâ, nesnelerin interneti (IoT), Makineden makineye (M2M), artırılmış gerçeklik ve bulut bilişim gibi kavramların teknolojik gelişmeleri dijitalleşme sürecinde entegre edilmesi ile daha farklı yaşama ve çalışma ortamlarının oluştuğu ve ilerleyen dönemlerde daha da artacağı ön görülmektedir. $\mathrm{Bu}$ bağlamda, dijital çağda yaşama ve iş yapma biçimleri hızlı bir dönüşüm içerisine girerek kabuk değiştirmektedir.

Örgütler de bu çağın getirdiği teknolojik hıza ayak uymak zorunda kalarak çeşitli değişimlerin içerisine girmişlerdir. Bilişim çağının ortaya koyduğu teknolojik devrimler, üretimde verilerin toplanmasını ile yapılan analizler sonucu daha verimli ve etkin iş modelleri ortaya çıkacağı ön görülmektedir. Örgütler bu süreçte teknolojinin hızla ilerlemesine yetişme de zorluk yaşadığı takdirde, ilerleyen dönemde zor ve karmaşık süreç yönetimleri de o doğrultuda zorlaşacaktır. Örgütlerin günümüzde kullandığı bulut teknolojilerinin yaygınlaşması ile birlikte, bazı iş alanlarının tamamen ortadan kalkacağı öngörülürken, belki de bilinmeyen farklı iş olanakları ortaya çıkacaktır. Dijital çağın getirdiği olanaklar sayesinde, iş gücünün eski çalışma yaşamındaki deneyimlerden daha farklı yeni çalışma ortamları BT ile mümkün kılınmaktadır. Dijitalleşme ile dünyanın neresinde olunmasından ziyade, neyin nasıl yapıldığı önem arz etmektedir. Son 20 yılda özellikle bilişim teknolojilerinin gelişmesi örgütlerde de bu dönüşümü gerçekleşmiştir. Günümüzde, örgütlerde bilgisayar kullanım becerileri yüksek olan kişiler ile çalışma isteği zorunluluk haline gelmiştir. Ayrıca BT uygulamalarının yaygınlaştığı bu dönemde çalışanların çalışma modelleri ile bilgi ve becerileri de bu dönüşümün içerisinde değişmiştir. Bu dönüşümün çalışanların üzerinde pozitif ve negatif etkileri olmaktadır. Bu çalışmada, dönüşüm süreci ile bilişim teknolojilerinin çalışanların üzerinde ortaya çıkardığı olumlu ve olumsuz etkilerine yönelik bir literatür taraması gerçekleştirilmiş olup, elde edilen bulgular doğrultusunda değerlendirmelerde bulunulmuştur.

\section{Dijitalleşme}

Dijitalleşeme kavramı bilginin sayısallaştırması olarak bilinmektedir. Elde edilen verilerin sayısallaştırılarak çeşitli platformlarda yer edinme sürecidir. Sayısallaştırma ise, analog işlemlerin bilgisayar ortamında depolanması ile sayısallaşan bir formatta dönüştürülmesi olarak söylenebilinir (Karakaş vd, 2009). Bu kavram iş modelinin dönüşüm içerisine girerek farklı bir değerler üretmede olanak sağlamak için dijital teknolojilerin kullanılmasıdır. Dijitalleşme, uyumlu olmayan bir bilgi iletişim teknolojisi altyapısına sahip olmak anlamına gelmemektedir. Sahip olunan kaynakların, işletmeye değer katacak sonuçlara dönüştürme sürecini ifade etmektedir. İşletmelerin yeni iş modelleri geliştirmesi, yeni ürün ve hizmetlerin yaratılması ve işletmenin sahip olduğu tüm kaynaklarını etkin kullanılabilmesi sürecinde teknoloji ile uyumlaştırabilmek anlamına gelmektedir (Accenture, 2015). Dijitalleşme, bir iş modelini değiştirmek ya da dönüştürmek için yeni bir kazanç ve değer üretebilecek firsatlar yaratabilmek için dijital teknolojilerin kullanılmaya başlanmasıdır. (Gartner Inc, 2020). Dijitalleşme, dijitalleştirilmiş verileri kaynaklarıyla ile dijital teknolojilerle iş sürecini etkinleştirmeyi, iyileştirmeyi veya dönüştürme sürecidir. Bu süreçte yaşanılan dijital dönüşüm kavramı ise, yetkinliklerin, iş faaliyetlerinin, süreçlerin ve modellerin dijital teknolojilerin farklılaşması ve firsatlarını ve toplum üzerinde yaşanan etkilerini öncelikli ve stratejik bir şekilde tam olarak kaldıracak derin ve hızlanan dönüşümüdür (i-SCOOP I).

Büyük verilerin her geçen saniye çoğalması ile ortaya çıkan dijital kaynaklardan ziyade bu platformların etkin biçimde kullanılmaları ve geliştirilmeleri de dijitalleşmenin bir parçasıdır. Dijitalleşme işletmelerin yeni fikirler geliştirmelerini, daha geniş bir kitleye ulaşmalarını, işlerini organize etmek ve yönetmek için gelişmiş araçlar kullanmalarını ve en önemlisi, müşterilerini mutlu etmek ve yaşam kalitelerini yükseltmek için daha iyi ürün ve hizmetler sunabilmelerini sağlamaktadır. Dijitalleşme kavramı ile ilgili RICOH şirketi bir araştırmada bulunmuştur. Almanya'da bulunan 1600 
KOBİ ile yapılan araştırmada, çalışanlara "dijitalleşme" sözcügünün şirketleri için hangi anlama geldiği sorulmuştur. Çalışanların \%86 gibi büyük bölümünün dijitalleşme ile şirketlerin esnek hale gelmesi ve piyasaya daha da hızlı bir şekilde uyum sağlayabileceklerini ifade etmişlerdir. Çalışanların

\%70'i ise teknoloji standartlarının artmasından dolayı şirketlerinin daha sağlıklı büyüyeceğini düşünmektedir. Çalışanların \%64'ü dijitalleşme ile üretilen bilgileri analiz etmek ve yeni piyasaların açmasına olanak sağlayacağını düşünmektedir. \%62 oranı ile birlikte dijitalleşmenin çalışanları olumlu etkileyeceklerini düşünmektedir. \%52'sinin ifadelerine göre şirketlerin dijitalleşmeye beş sene içinde yatırım yapıldığında bulundukları piyasalarda tutamayacakları ifade etmiştir. Dijital kaynaklarda dijitalleşmeyle ilgili son gelişmeler ve beklentileri rapor edilmektedir. İş dünyası ve ekonomistler, dijital altyapının yavaş yavaş genişlemesini takip etmektedirler. Dijitalleşme modern yaşamın ve işletmelerin temel bir unsuru olarak görülmektedir (scientu.net, 2018)

TING 2020 Dijital Düşünme Raporundan alınan verilere göre dijital düşünmenin eyleminin, müşterilerin beklentilerini algılama ve çalışanların memnuniyetini her aşamada yükselten ve başarının anahtarı olduğunu düşünülmektedir. Dijital düşünme araştırmasına katılan şirketler, bu kapsamda dijital düşünmenin bileşenlerine değinmişlerdir. Katılımcıların dörtte üçü bu yetkinliklerle dijital teknolojilerden müşteri beklentilerinin daha iyi karşılanması, veri temelli hale gelinmesi ve iş süreçlerinin kısalması ve iyileşmesi yönünde beklentileri olduğunu dile getirmiştir. Dijital teknolojilerin bu özellikleri ile esnek, daha hızlı ve yaratıcı çözümlerin ortaya çıkması ve yeni dönem iş hayatının oluşmasında kilit rol haline gelmiştir. Raporda, dijitalleşmeyle şirketlerin teknolojiyi çalışan memnuniyeti, esneklik, çeviklik, iş birliği ve iletişim gibi faktörlerle birleştirmesi ve işgücü için dijital bir deneyim yaratmaları gerektiği belirtilmiştir (marketingturkiye.com, 2020).

Dijitalleşme yaşamın her alanına müdahale etmektedir. Teknolojinin hızla ilerlemesi ile birlikte Dünya dijital çağa ayak uydurmak zorunda kalmıştır. Örgütler de bu dönüşümden bir parçası olmuştur. Dijitalleşme ile örgütler gerekli yazılım uygulamalarını edinip, iç yazışmalarını hem dijital ortama aktarmış hem de donanım malzemelerini dijital dünya ya uyumlu hale getirmiştir. Dijital dönüşüm sürecinde gerek üst yönetim gerekse alt çalışanlar büyük çaba sarf etmek durumunda kalmıştır. $\mathrm{Bu}$ dönüşüm sürecinde gerekli ekipmanların ve araçların zamanında temin edilmesi ve gerekli bilgilendirilmelerin etkin bir şekilde yapılması büyük önem arz etmektedir. Dijitalleşmenin örgütler için çoğunlukla pozitif etkileri mevcut gözükmektedir. Ancak dijital dönüşüm sürecinde çalışanların bu sürece ayak uydurmaları için örgütlerin yüklendikleri sorumlulukların yerine getirilmesi gerekmektedir. Örgütler çalışanların dijital teknolojileri kullanmaları konusunda teknik destek ağları sunularak onların ihtiyaç duydukları eğitimleri almalarını sağlamalı ve bu uygulanan teşviki sürdürülebilir hale getirmelidir. Dijital dönüşüm aniden gerçekleşen bir eylem olmadığı gibi, bu dönüşümün belirli bir noktada bitmeyeceği bilinmektedir. Dolayısı ile bu süreçte bütüncül bakış açısı önemlidir. Dijital çağın getirdiği yeni teknolojilerle bu dönüşüm süreci sürekli devam edecektir. Çalışanların yeni teknolojiler kullanma konusunda girişimlerde bulunmaları örgüt tarafından desteklenmeli ve örgüt genelinde uygulamalarda esneklik sağlanmalıdır (Digital University, 2016).

\section{Bilişim Teknolojileri}

Bilişim teknolojileri genel anlamı ile bilginin yönetilmesi ve işlenmesi için ilişkili teknolojilerin içinde yer aldığı kapsamlı bir unsurdur. Bilişim teknolojileri kavramı bilginin elde edilmesi, işlenmesi, saklanması ve ihtiyaç duyulduğu zaman gerekilen yerlere gönderilmesi veya herhangi bir ortamdan istenilen bu bilgiye erişim imkanı sağlayan teknolojiler olarak belirtilmektedir (Ceyhun ve Çağlayan, 1997). BT, bilgisayar donanımları ve yazılımları ile internetin dâhil olduğu bir bilgi ağlarının tasarlanması, geliştirilmesi ve yönetilmesinden sorumludur. Bu süreçte bilgisayarların küresel olarak rolü oldukça büyüktür çünkü endüstriyel çağdan bilgi çağına geçişte önemli bir değişim aracı olmuştur. Özellikle çalışma hayatına yön veren araçları ile günlük çalışma hayatının merkezinde yer 
almaktadır. BT uygulamalarının arasında yer alan iş hayatındaki e-mail, web tarayıcıları, banka işlemleri, bilgisayar destekli her türlü ortamlar, ATM'ler, bankacılıkta yapılan EFT işlemleri, barkod tarayıcılar ve satın alma noktası yer alan cihazların çalışma yaşamında ki önemi büyüktür(Irwin ve Michael, 2003). BT'nin gelişmesi ile çalışma yaşamında, çeşitli ihtiyaçlar doğrultusunda yapılması gereken çeşitli programlar ve donanımlara yönelik alanında yetkin ve çeşitli özellikler ve nitelikli mühendisler, sistem analiz uzmanı, yazılımcı ve programcılara ihtiyaç duyulmuştur. BT’nin kullanımıyla ilgili iş basamaklarında örgütün bilgi ve iletişimdeki dönüşümünün üretim, satış, pazarlama ve genel olarak yönetim sistemlerinde ortaya çıkardığı yeni özellikleri entegre eden yeni ekonomi, işsizliği azaltan, yeni iş imkanları ve meslekler oluşmasında diğer yandan etkisizleştirilmiş ve örgütlenmemiş çalışanların korunmasız bir şekilde istihdam edilmelerine yol açmaktadır (Keser, 2004). Bu bağlamda, BT'nin yaygınlaşması ile gerçek önemine kavuşan otomasyon sistemlerindeki işlemlerin önemli şekilde yükselişinin arkasında yer yer alan en önemli kaynak, insan beyninin iş süreçlerine dahil edilmesi ile oluşmaktadır. Kurumlarda ileri Bilişim teknolojileri araçlarının oldukça geniş bir şekilde yaygınlaşmasıyla birlikte özerk, program tasarlamada ve işin bütün aşamalarına karar verme konusunda istekli ve bilgili BT çalışanlarına daha çok ihtiyaç duyulmaktadır (Castells, 2000). Bu süreçte, bilişim teknolojilerinin yaygınlaşması ile mavi yakalı çalışanların performansının etkilendiğini vurgulamaktadır (Debela, 2009). Bilgisayar uygulamalarının onları eskisinden daha verimli çalışanlar haline getirdiğini savunmuştur. Bununla birlikte son yıllarda bilişim teknolojileri, kuruluş planlama, kontrol, yönlendirme, bütçeleme ve raporlamaya yardımcı olduğundan örgütler için oldukça önemlidir. Bilgisayar teknolojisi uygulamaları ve internet, topluma önemli katkı ve fayda sağlamıştır. Özellikle, sağlık, askeri, yarg1, iş dünyası, eğitim ve toplumunun diğer alanlarında çalışanların hayatını kolaylaştırdığ alanında, kritik operasyonel yönetim ve karar verme, operasyonel yöneticiler ve yöneticiler için karmaş1k durumlar ile karşılaşmada da performansın iyileştirilmesi gibi hizmetlerin standartlaştırılmasını sağlamaktadır. Güçlü iş birliği çeşitli faaliyetlerle sürdürülebilir tüketici ilişkileri hizmetleri ve örgüt çalışanları ve gerçek tüketiciler arasında zaman iletişimi sağlamaktadır. Örgütlerde Bilişim teknolojileri hizmet sunumu, operasyon yürütme, dönüşüm ve ürünlerin tamamlanmasında iyileştirmelere katk1 sağlamıştır. BT' nin örgütlerde yaygınlaşması ile firmaların standartlaştırılmış iş tanımlarının ve eğitim programlarının katı çalışma prosedürlerinin etkisinde rutin bir hale dönüşmesine sebep olmuştur. BT'nin çalışma hayatına sunduğu esnek çalışma modeli, çalışanların bireysel-izole bir şekilde iş görme özelliklerinden dolayı onların işgücünün ortak amaçlar bir araya gelmesi durumlarında yönetilmesinde ve ortak bir örgüt kültürünün yaşanmasını zorlaştırmaktadır (Keser, 2004). Dolayısıyla, örgütlerin dijitalleşme sürecinde bu tür olumsuzlukları yaşamaları oldukça mümkündür.

BT ile yapılan çalışmalar sonucunda örgütsel yapıyı, çalışanları, çalışanların kullandıkları sistemleri, iş yapış şekillerini, çıktıları ve içinde bulunulan çalışma ortamını etkilenmektedir (Yücel ve Erkut,2010).Yaşanan bu gelişmeler doğrultusunda çeşitli çalışma modelleri de ortaya çıkmıştır. Bu dönüşüm sürecinde, geleneksel çalışma sistemlerine ek olarak, proje bazlı, kısmi zamanlı esnek, çağrı üzerine, uzaktan ve evden çalışma gibi yeni çalışma sistemleri ortaya çıkmıştır. Dijitalleşme sürecinde oluşan teknolojik ilerlemeler üretimin şeklini ve yapısının bir dönüşüm yaşamasına, değiştirmiş esnek üretim sistemleri Fordist üretim yapısının yerine geçerek esnek çalışma ya da standartsız bir çalışma olarak adlandırılan çalışma disiplinlerini artırmıştır (Parlak ve Özdemir, 2011). Çalışanlar BT'nin sunduğu uygulamalar sayesinde esnek çalışma ortamlarına sahip olmuşlardır. Çalışanlar BT' nin sunduğu çalışma ortamları sayesinde işlerini evden de yürütebilme imkânını sağlamışlardır. Bu durum çalışanların gün içerisinde daha sakin, daha motive olmasını sağlamaktadır. Çalışanların iş-ev arası yaşadıkları yol yorgunluğu ve sabah erken saatlerde kalmalarına gerek duymadan çalışmaları da performansı etkin ve verimli şekilde sürdürülmesini sağlamaktadır.

Dünyayı 2019 yılının sonlarına doğru etkisi altına alan ve 2020 Mart ayında ise Türkiye'de de ortaya çıan pandemi (Covid 19 salgın hastalığı) ile çalışanların büyük bölümü işlerini evlerinden yürütme durumunda kalmıştır. Üniversitelerin tatil edilmesi ile öğretim elemanları derslerini evlerinden 
yürütmek durumunda kalmışlardır. Yaşanılan bu durumun çalışanların performans ve verimliliklerinde olumlu ve olumsuz etkileri bulunmaktadır. BT sayesinde Uzaktan Eğitim uygulamalarını kullanabilme bilgisi bulunan çalışanlar evden çalışmanın getirdiği kolaylık ile bu durumun olumlu etkilerini yaşamaktadır. Ancak, Uzaktan eğitim uygulamalarını kullanarak ders anlatmaya çalışmada ve teknolojiyi kullanmada eksiklik yaşayan çalışanlar psikolojik olarak bu durumun getirdiği zorluklarla başa çıkmak durumunda kalmışlardır. Öte yandan örgütlerin BT uygulamaları sayesinde diğer çalışanlarına uyguladıkları evden ve dönüşümlü çalışma modeli çalışanların gün içerisinde maruz kaldıkları yol-iş arası yorgunluğun ve iş ortamlarının getirdiği olumsuzluklardan dolayı daha verimli çalışma sürdürebilmelerini sağlamıştır. Ancak, çalışanların teknolojiyi kullanması ile çeşitli problemlerde beraberinde ortaya çıkabilmektedir. Çalışanların yaşamlarını oldukça etkileyen BT uygulamaları ile çalışanlar işlerini ev ortamlarına da aktarmaktadır. Ancak bu tür problemler çalışanların iş-aile yaşam dengesinde problemlere sebep olabilmektedir. Çalışanların evde olmalarından kaynaklı esnek çalışmaya dayalı uzun süre çalışma saatleri ile ailelerine daha az vakit ayırmaları, aile ilişkilerinde problemlere ve ciddi oranda rol çatışmasına sebep olmaktadır. $\mathrm{Bu}$ durum iş ve aile yaşamlarından kaynaklanan rol arzu-taleplerinin bazı yönleriyle birbirleriyle uyumsuzluk yaşanması durumu olarak ifade edilebilinir (Greenhaus vd., 1985). Bu durum çalışanların verimliliğinde ve performansında yorgunluğa sebep olacağından olumsuz etkilere sebep olmaktadır. Bununla birlikte çalı̧̧anlar, çalışma süreleri boyunca bilgisayar ya da tablet gibi teknolojik aletlerin sebep olduğu çeşitli rahatsızlıklara maruz kalmaktadır. Gün boyu oturarak çalışmak çalışanların ellerde, kaslarda ve bileklerinde yorgunluğuna sebep olmaktadır. Bilgisayar kullanımı sebebiyle değişen bir duruşlar ile bileklerde ve kol kaslarının bunun gibi hareketleri tekrarlamasını gerektirmektedir. Dolayısıyla, omuz, omurga, sırt, dirsek, el bileği ve parmaklara ilişkin rahatsızlıklar sık görülmektedir. Bilgisayar kullanımı ile gözler de birçok problem ortaya çıkabilmektedir. Bilgisayar kullanımına bağlı gözlerde yanma hissi, yorgunluk, kızarıklık, sulanma, bulanıklık, kaşıntı ve çift görme gibi problemler oldukça sık görülmektedir. Ayrıca, monitörlerden çıkan radyoaktif dalgaların göz rahatsızlıklarına sebep olduğu görülmüş̧ür. Bu durumda, iş yerlerinde yapılan bazı düzenlemeler ve kullanıcıların eğitimi ile bu sorunların bir kısmı önlenebilir(İnandı ve Akyol, 2001). Teknolojinin sebep olduğu bu tür fiziksel problemlerin ortaya çıkması da çalışanların verimliliği ve performansında önemli etkilere sahiptir. BT'nin getirdiği bir diğer olumsuzluk ise çalışanların iş yerlerinde yaşadıkları, verimlilik düşüşünde ve işgücü kayıplarında önemli etkiye sahip olan siber aylaklıktır. Bu durum çalışanların performansında düşüşlere sebep olabileceğinden örgüt yöneticilerinin de üzerinde yoğunlaştıkları bir husustur. Siber ayaklık, çalışma saatleri süresince işle ilgili olmayan amaçlar için internet kullanımı olarak tanımlanan bir kavramdır (Lim, 2002). Çalışanların işyeri tarafından sağlanan teknolojik araçlarla yapıldıkları, kişisel işlemlerine yoğunlaştığı, çalışma saatleri içerisinde yapıldıkları ve istendik eylemleri oldukları olarak da düşünülebilinir. İşyerinde bilinçli olarak internette zaman kaybetmeye yönelik faaliyetler olarak da görülmektedir (Johnson ve Indvik, 2003). İş ile ilgisi olmayan amaçlarla, işle ilgili olmayan internet sitelerinde gezinmek için çalışma saatlerinde şirketlerinin internet erişimini kullanan çalışan davranışı olarak tanımlanmaktadır. Siber aylaklık davranışını olumsuz olarak gören araştırmalara göre siber aylaklık üretim karşıtı sapkın davranışlar olarak da nitelendirilmektedir. Siber aylaklığın olumsuz sonuçları ile ilgili alan yazın incelendiğinde genel olarak verimliliği düşürdüğü görülmektedir (Kara, 2020). Bu durum çalışanların verimliliğini ve performansını etkilediği için teknolojinin getirdiği dezavantajlardan biri olduğunu söyleyebiliriz. 


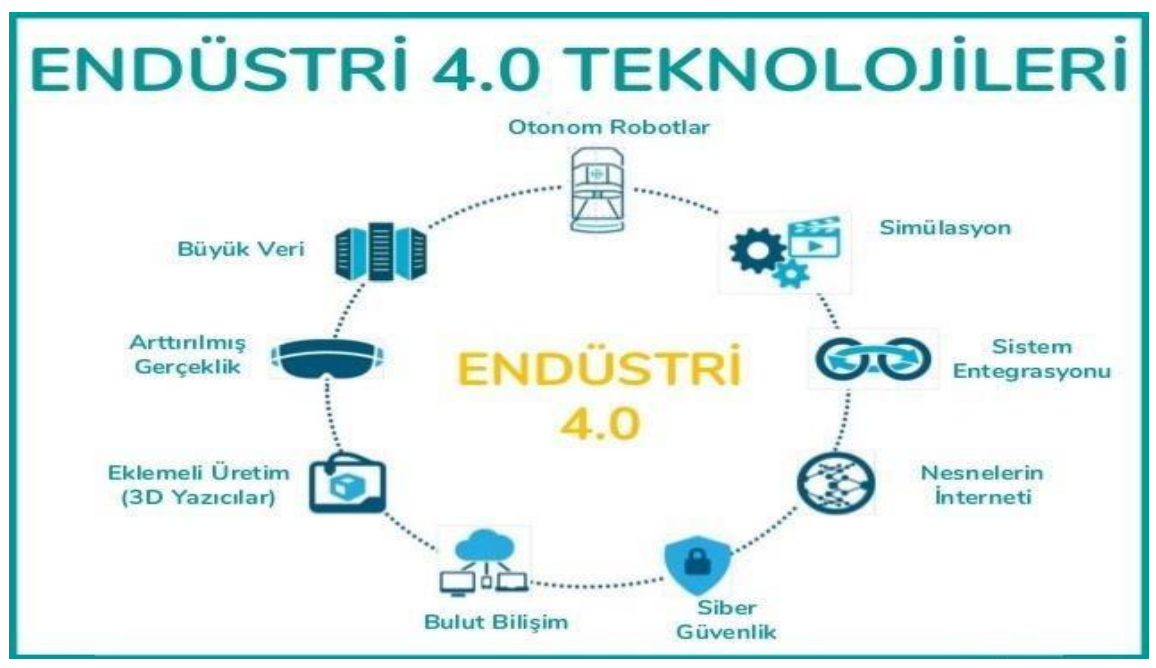

Şekil 1: Endüstri 4.0 teknolojileri (httpswww.a24.com.trendustri-40-nedir-ne-anlama-geliyor haberi40128320h.htmlh=50)

Öte yandan Endüstri 4.0 teknolojisi ile nesnelerin interneti, büyük veri, artırılmış gerçeklik, bulut bilişim, 3D yazılım, robotlar, otonom robotlar gibi teknolojilerin daha da gelişeceği ve artacağı ön görülmektedir. Günümüzde bilgisayar teknolojileri sayesinde zeki insanların dahi yapamadığı işler yaptırılabildiğinden, bu durum, teknolojinin gelecekteki son noktada olmayacaktır. Bu süreç sosyal hayatta, ekonomide, çalışma hayatında ve günlük olarak yapılan işlerde hayatın her alanında kendini belli etmiştir. Bu durum olumlu-olumsuz çeşitli sonuçlara neden olmuştur. Özellikle, Endüstri 4.0 teknolojisi sayesinde yapılan üretimler ile bir çı̆̆ır açacağı görüşleri de oldukça fazladır. Çalışanların üretim süreçlerinde hangi pozisyonda olacakları konusunda büyük bir çelişki yaşanmaktadır. Bu süreçte işsizlik ve istihdam alanında yaşanması muhtemel olumsuzluklar gündemi oldukça meşgul etmektedir. Bu konuda kesin bir cevap bulunmamaktadır. Ancak, önceki sanayi devrimlerinin yaşanan böyle kaygılar, yerini her yeni teknolojik gelişmenin sunduğu yeni iş mecraları ve çalışanların becerilerin gelişmesini de beraberinde getirebildiğinden işsizliğin uzun vadede çoğalması beklenmemektedir (Taş, 2018).

Son yıllarda gündemde olan Endüstri 4.0 teknolojileri ile akıllı teknolojiyle donatılmış fabrikaların ön planda yer alacağ bir dönüşümün gerçekleşeceği öngörülmektedir. Endüstri 4.0, insana benzeyen robotlar ve akıllı makinelerin üretimde hâkim olacağ 1 bir dönemi tanımlanmaktadır. Teknolojiye bağlı olarak üretim yapısı köklü bir değişime uğrarken, dijital bir dönüşümün sonucu olarak yapay zekâ teknolojisi ile donatılmış makinelerin üretiminde kullanılmasıyla birçok mühendislik alanında yenilik yaşanacağı söylenmektedir. BT 'deki değişimin işletmeler üzerindeki etkileri geçmişten beri tartışılmaktadır. Ancak Endüstri 4.0 ile birlikte, dijital dönüşümde yaşanan gelişmelerin boyutu çok daha hızlı ve etkin olma özelliği göstermektedir (Kara, 2020).

BT küresel dünyanın ülkelerin gelişme sürecini büyük ölçüde etkilediği kaçınılmaz bir sondur. Her geçen dakika yapılan yenilikler ve güncellemeler ile bilişim sektöründe dünyayı yakalamak oldukça zorlaşmaktadır. BT’nin çalışanlar tarafından nasıl bilindiği konusunu ölçmek ve hangi koşullarla BT'nin ilişkili olduğunu tespit edebilmek için yapılan araştırmada, BT kullanımına dair farkındalığının düşük düzeyde olduğunu saptanmıştır. BT’nin çalışanlar tarafindan bilgisayar kullanımı olarak algılandığı görülmüştür. Bilgisayar, çalışanların çalışma hayatlarında işlerini kolaylaştıran ve eğlenceli ancak çoğu zaman kullanım zorlukları çıkaran bir araç olarak düşünülmektedir. Çalışanların çoğu bilgisayar kullanmanın kendileri için bir statü olduğu düşünmektedir. Frekans analizine bakıldığında MS Excel, MS Word gibi sistem kullanımını temsil eden değişkenlerin kullanım oranı \%50'lerde iken, her gün bilgisayar kullanıyorum diyen çalışanların oranı \%65'dir. $\mathrm{Bu}$ durum her gün teknoloji ile iç içe 
olunmasına rağmen çalışanların BT 'yi benimseyemediğini göstermektedir. BT ile çalışanların akıllarına ilk gelen şey, hızlı ve kaliteli olmasıdır. Ancak aktif sistem kullanım oranı \%50'yi bulmadığı için kalite ve hız parametrelerinin etkinliğinden söz edilmemektedir. Çalışanların oranı \%48' i BT konusunda eğitim almadığını söylemektedir. Çalışanların işe alımlarında uzmanlaşmış eleman seçimi yapılmamaktadır. Çalışanların \%85'i yaklaşık bir yıldan daha uzun zamandır bilgisayar kullanmaktadır. Ancak bu çalışanlar BT'yi kullanma konusundaki eksikliklerinin farkında değildirler. Çalışma sonucunda, çalışanların BT'nin maruz bıraktığı etkilerin cinsiyet, tecrübe düzeyi gibi parametrelerden etkilendiği gözlenmiştir (Aksoy ve Kara, 2013)

Dijitalleşeme ile kâğıt üzerinde yazılı metinler dijital ortama aktarılma dönemi BT desteği yaklaşı 10 senedir etkin bir şekilde kullanılmaktadır. Özellikle kamu kurumlarının üzerinde durduğu Elektronik Belge Yönetim Sistemleri çalışanların işlemlerini kolaylaştırmak ve kâğıt kullanımını azaltmada dönüşüm sağlayan yazılımlar haline gelmiştir. Belge yönetim kültürünü anlamlaştıran EBYS programı kurumların belge transfer sürecinde süreçlere hız ve kalite kazandırmaktadır. Sistemi kullanan çalışanların iş yapma yöntemlerinde değişim yaşanmasına sebep olmuştur. EBYS kullanıma ilişkin çalışanların EBYS kullanmalarına yönelik çalışma sonuçlarına göre, dış faktörleri olarak bilinen kaygı, özyeterlik, kolaylaştırıcı koşullar ve sosyal etki değişkenlerinin EBYS'ye yönelik algılamalarda en belirleyici özellikler olduğu görülmektedir (Esen ve Büyük, 2014).

\section{Sonuç ve Öneriler}

Günümüzde, iş ortamında meydana gelen hızlı değişikliklere yeni yollar arayan örgütler, bilişim teknolojilerini kullanarak değişen dünyaya uyum sağlayarak kendilerini farklılaştırmaktadır. Bilişim teknolojileri örgütlerin rekabet gücünü artırmak ve veya rakiplerine göre rekabet avantajı sağlamak için bir araç olarak kullanılmaktadır. Örgütlerin yeni bilgi çalışma sistemleri aracılığıyla bilgi, şirket çapında veri ve iletişim ağlarına erişim sağlamada destek sağlamaktadır. BT kavramı kapsam açısından daha geniş bir düşünülebilir. Donanım, yazılım ve veri iletişimi ile sınırlı olmamalıdır. BT, ileri teknoloji ve internet çalışma altyapısı ve mimarisinde ortaya çıkma ve ilerleme, insan çabasının tüm boyutlarında büyük ölçüde bir devrime neden olmuştur. Teknolojik ilerleme, BT uygulamaları ve teknolojik unsurlar, işletmelerin ve kamu kurumlarının dinamiklerini değiştirmiştir. BT ilerlemesi ve internetin yaygınlaşması ile çalışanlar endüstriyel çağdan bilgisayar ve bilişim çağına (Dijital çağ) dönüşüm yaşanmıştır. BT ile yoğun yapılan faaliyetler, internet ile birbirine bağlandığı dijital dünya haline gelmiştir. Bilgisayar bir kaynaktan diğerine bilgi göndermeyi daha kolay ve basit hale getirmiştir. BT farkındalığı ve kullanımı, iletişim ağının yüksek standardı nedeniyle hemen hemen her ofiste bulunmaktadır. BT uygulamaları ve güçlü internet çalışma altyapıs1, örgütlerde firsat kaynaklarına neden olmuştur. Teknolojik ilerleme ve bilgisayar modernizasyonu, bilginin dönüşümünü her zaman ve her yerde kolay ve hılı hale getirmiştir. BT tabanlı sistem uygulamaları ve internet çalışma altyapısı, örgütlerin verimliliğini ve esnekliğini geliştirmiştir. BT tabanlı stratejiler sayesinde örgütlerin iş modelleri de değişmektedir. BT uygulamaları ve internet çalışma altyapıları yaşamsal gelişim, gelişme ve kaynakların hayata geçirilmesinin vazgeçilmez araçları haline gelmiştir. Dijitalleşmenin sunduğu imkânlar dâhilinde çalışanlar mekan ve zaman dinlemeden çalışacakları zamanı seçebilmektedirler. Elde edilen veriler dijital formatlara kolayca dönüştürülebilmekte ve dijital platformlarda saklanabilmektedir. Çalışanlar işlemlerini mobil telefonlarına indirdikleri BT uygulamaları sayesinde yapabilmektedir. Teknolojinin bu denli ilerlemesi ile iş planlamaları çalışanların yaşam tarzına göre ayarlanmasını mümkün kılmaktadır. Dijitalleşme sürecinde BT'nin sunduğu araçlar kullanılarak daha fazla şirket serbest çalışma, mobil odaklı çalışma, evden çalışma gibi esnek çalışmalar desteklenmektedir. $\mathrm{Bu}$ bağlamda, BT uygulamalarının faydaları saymakla bitmemektedir. BT uygulamasından sorumlu yöneticilerin çalışanların daha aktif ve verimli bir şekilde çalışmaları hususunda BT teknolojilerinin güncel gelişmelerini daha yakından takip etmeli ve çalışmaların BT uygulamalarına yönelik teşvikinde öncülük etmelidir.

Son dönemlerde popüler bir konu haline gelen Endüstri 4.0 'in ve ülkemizde uygulamalarının çalışma yaşamına girmesi ile istihdamda zorluk ve işsizlik olacağına yönelik görüşler bulunmaktadır. Örgütlerin ve özellikle çalışanların yaşanacağı ön görülen bu probleme yönelik önlemler alması zorunluluk arz etmektedir. 
Çalışanların teknoloji odaklı eğitimler ile yönlendirilmesi, BT uygulamalarını kullanma becerilerinin artırılması, karar verme, uygulamalar geliştirme odaklı iş modellerinin geliştirilmesi gerekmektedir. Çalışanların iş tanımlarının değişeceği ve BT' nin çalışma yaşamında daha da önemli bir yer edineceği kaçınılmazdır. Çalışanlara verilecek eğitimler, yetenekli genç beyinlerin üretim odaklı çalışma yaşamında yeni iş alanları geliştirmeleri ve yüksek düzeyde teknolojinin kullanıldığı iş ortamlarının oluşturulmasında rol almaları bu süreçte etkili olacaktır. 4.Sanayi devriminde daha çok üretim odaklı bir ülke oluşumunun hayata geçirilmesi gerekmektedir. Ayrıca ileri düzey araştırmalar ve çalışmalara yönelik örgütlerin yatırımlarını AR-GE ile desteklemeleri de önem arz etmektedir. Dijital dünyanın ve yapay zekâ teknolojilerinin entegre edildiği bu dönem, çalışanların hayatını zorlaştırmaktan ziyade niteliklerini değiştirmelidir. Çalışanların yaşam şekillerinin de bu yönde dönüştürülecek hem performans hem de verimliliklerinin artırılmasına odaklanmak dijitalleşme sürecinde başarılı olma hususunda büyük rol oynayacaktır.

\section{KAYNAKÇA}

Aksoy, R., Kara,A. (2013). "Bilgi Teknolojilerinin Çalışanlar Tarafından Benimsenmesi: Karadeniz Ereğli'de Kobi Çalışanları Üzerine Bir Uygulama”. Uluslararası İktisadi Ve İdari İncelemeler Dergisi, (10).

Castells, M. (2000). "The Rise Of The Network Society”. Oxford: Blackwell Publishers.

Ceyhun Y. Ve Çağlayan U., (1997), " Bilgi Teknolojileri Türkiye İçin Nasıl Bir Gelecek Hazırlamakta”, Ankara: Türkiye İş Bankası Kültür Yayınları, Genel Yayın No: 361, Ticaret Basım Sanayi.

Debela, T. (2009) "Business Process Reengineering İn Ethiopian Public Organizations: The Relationship Between Theory And Practice". Journal Of Public Management And Development, 1, 20-59.

Esen M., \& Büyük, K.(2014)” Teknoloji Kabul Modeli Bağlamında Elektronik Belge Yönetim Sisteminin İncelenmesi: Yükseköğretim Kurulu Örneği”. Dumlupınar Üniversitesi Sosyal Bilimler Dergisi, (42).

Gartner Inc. (2020). Digitalization.(Erişim:01.05.2020),https://www.gartner.com/en/informationtechnology/glossary/digitalization

Greenhaus, Jeffrey Ve Nicholas J. Beutell; (1985), “Sources Of Conflict Between Work And Family Roles”, The Academy Of Management Review, 10(1), Ss. 76-88.

İnandı, T., Akyol, İ. (2001),Bilgisayar Kullanımı İle İlgili Sağllk Sorunları, Sürekli Tıp Eğitimi Dergisi, 10(3). İnternet: 05.05.2020, $\mathrm{Https://scientu.net/dijitallesme1/}$

İnternet:(Erişim:14.05.2020)https://www.accenture.com/t20151117t010853_w/nlen/_acnmedia/accenture/conv ersion-assets/microsites/documents11/accenture-technology-vision-2015.pdf

İnternet: https://Erişim:18.05.2020)//www.marketingturkiye.com.tr/haberler/dijital-dusunme-arastirmasina-goresirketlerin-yuzde-70inde-dijital-strateji-var/

Irwin, A., \& Michael, M. (2003)." Science, Social Theory \& Public Knowledge”. Mcgraw-Hill Education (Uk).

İ-Scoop I. "Digitization, Digitalization And Digital Transformation: The Differences", Retrieved From Https://Www.İ-Scoop.Eu/Digitization-Digitalization-Digital-Transformation-Disruption/

Johnson, P. R., Indvik, J. (2003). “The Organizational Benefits Of Reducing Cyber Slacking İn The Workplac 
Proceedings Of The Academy Of Organizational Culture", Communications And Conflict, 7 (2), 53-60

Kara, M. A. E. (2020). “Örgütsel Davranış Üzerine Güncel Çalı̧̧malar”. Hiperlink Eğit. İlet. Yay. San. Tic. ve Ltd. Sti.

Karakaş, S., Rukanc1, F. ve Anameriç, H. (2009).” Belge Yönetimi ve Arşiv Terimleri Sözlüğü”, Devlet Arşivleri Genel Müdürlüğü, Yayın No: 24, Ankara

Keser, A. (2004). "Yeni Ekonomi Çerçevesinde Çalışma Hayatında Yaşanan Dönüşümler”, İ̧̧ Güç Ve Endüstri İliskkileri ve İnsan Kaynakları Dergisi, 6 (1),

Lim,V.G.K. (2002).”The It Way O Loafing Onthe Job: Cyberloafing, Neutralizing And Organizational Justice”,

Journal Of Organizational Behavior,23, 675-694.

Kurtulmuş N. (1995).’’Post-Endüstriyel Ekonomilerde Kitle Üretimine Bir Alternatif:Esnek Uzmanlaşma”. Sosyal Siyaset Konferansları Dergisi

Oxford-“Big Ideas Geography History”. Ch. 5, The Industrial Revolution, P. 290, RetrievedFrom,

Parlak, Z., \& Özdemir, S. (2011, June). "Esneklik Kavramı ve Emek Piyasalarında Esneklik”. In Conference Journal Of Social Policy/Sosyal Siyaset Konferanslar Dergisi (No. 60).

Taş, H . (2018). “Dördüncü Sanayi Devrimi'nin (Endüstri 4.0) Çalışma Hayatına ve İstihdama Muhtemel Etkileri”.

Opus Uluslararası Toplum Araştırmaları Dergisi , 9 (16) , 1817-1836.

The 2018 Digital University: "Staying Relevant İn The Digital Age" (2016) Erişim:08.05.2020,Http://www.pwc.co.uk/assets/pdf/the-2018-digital-university-staying-relevant-inthedigital-age.pdf

Yücel, D., \& Erkut, H. (2010). "Bilişism Teknolojilerinin Çalışma Yaşam Kalitesi Üzerine Etkisi”. İtü dergisi/D, 2(2). 